\title{
Safe and Local Supplier Approval - A Case Study of the Third Party Supplier Approval Scheme for Micro and Small Food Businesses
}

\author{
Richard Bradford-Knox \\ RBK Consultants, Food Safety, Gap Analysis and Risk \\ Management Research, United Kingdom
}

\author{
Kevin Kane \\ Salford Business School, University of Salford, United Kingdom
}

\begin{abstract}
:
It has long been recognised by many that micro and smaller food manufacturing or supply businesses have difficulties in meeting the food safety standards designed for larger food businesses and demanded of them by their customers. The consequence of this has been that the buyers have lacked sufficient confidence in the food hygiene and food safety of their products. In 2005 certain individuals and organisations within or related to the food industry got to together to design and develop a standard or scheme that, if met, could provide sufficient assurance that their standards of food hygiene and food safety management controls minimised any risk of harm to their customers or consumers.
\end{abstract}

This case study examines the factors that inspired the need for Safe and Local Supplier Approval (SALSA), the third party supplier approval scheme, and led to its development, how it compares to other private standards and its potential for future development. It also seeks to show how SALSA and the principles it follows fit in with the principles of risk based management systems through support, cooperation, between the various parties and businesses involved together with a sound governance structure in order to achieve successful outcomes.

Paper type: Research paper

Keywords: Micro and Small Food Businesses; Third Party Auditing Systems; Food Safety; Cooperation 


\section{Introduction}

Micro, small and developing businesses have difficulties in addressing certain issues in order to meet compliance with food safety law and industry best practice compared with larger businesses. These issues or barriers have been found to be mostly related to insufficient human and financial resources to support and implement risk based food hygiene and food safety management systems (Panisello and Quantick 2001; Taylor, 2001; Taylor and Kane, 2005; Yapp and Fairman, 2006; Fielding et al., 2011).

Mensah and Julien (2011) proposed that the challenges faced by larger companies are not significantly different from those faced by smaller businesses but the limited capability as well as limited resources makes food safety compliance a heavy burden. One of the key findings relating to Small and Medium Enterprises (SMEs) is that they find it harder to overcome the problems of implementing and complying with the risk based Food safety management systems based on the principles of Hazard Analysis Critical Control Point (HACCP) as required by law as well as by their customers (Mensah and Julien, 2011).

According to Psomas et al. (2010) these issues are also common to food businesses and other businesses that are required to or choose to implement management and quality systems to satisfy customer needs and expectations. For example the same factors have been found to apply to effective implementation of ISO 9001 in SME service companies. These include continuous improvement of processes, product quality, management commitment, employee training and the need to reduce customer complaints.

As a way of addressing these issues Safe and Local Supplier Approval (SALSA), a food safety standard or scheme, was launched in March 2007 to support small businesses by providing a food safety management assurance standard designed to meet the requirements of customers in the retail, catering and the hospitality sectors of the food industry. The scheme was launched as a 'not for profit joint venture' between four main trade associations consisting of the British Retail Consortium (BRC), National Farmers Union (NFU), the Food and Drink Federation (FDF) and the British Hospitality Association (BHA) (SALSA, 2014a).

SALSA's potential was also recognised by DEFRA, Food Standards Agency (FSA) and Scottish Enterprise who assisted with its development and provided start-up funding (Grimes, 2011).

The SALSA web site (SALSA 2014a) describes it as a food-safety standard written by experienced food safety experts to reflect both the legal requirements of producers and the enhanced expectations of 'best practice' of professional food buyers with experienced and professional expertise provided by the Institute of Food Science and Technology (IFST).

IFST describes SALSA as a rigorous food safety certification scheme which assists local and regional food and drink producers who supply their products to national and regional 
buyers by removing many of the practical barriers that prevent small producers from directly supplying retailers and caterers (IFST, 2013).

As described on its web site SALSA is designed to suit the needs and means of small producers and manufacturers with the attraction of keeping the cost of gaining a recognised approval or certification at a different level than other approval schemes designed for larger operations.

Other benefits of SALSA is the provision of training and guidance through a mentoring service as part of a food suppliers development process and potentially as a stepping stone to other food safety and quality certification such as BRC (SALSA, 2014b).

Since 2007 it has grown steadily to have, by September 2011, there were 2,246 registered suppliers and 838 registered buyers, with over $70 \%$ of them were micro businesses (Grimes, 2011).

\section{Definition of Micro and Small Businesses}

In the absence of other official definitions of what constitutes a micro or small business for the purposes of this research is the definition given by The European Commission. This defines a micro business as one that has 10 employees or less and a small business as one that has 50 employees (The European Commission, 2005).

Taylor (2001), in her work' HACCP in small companies: benefit or burden?', proposes that small companies generally share the following qualities:

1. A limited share of the market.

2. Are owned by one person or a small group of people.

3. Are mostly owner managed and independent of ownership by larger groups of companies.

At the commencement of the scheme in 2007 the SALSA management's definition described suppliers that would typically use the scheme as those who:

- employ fewer than 20 full time production staff

- have a turnover of less than $£ 2$ million

- can be audited in approximately half a day

- already supply national buyers on a local or regional level

- supply from a defined locality, area or region - 'locality food' (with fewer than 20 full time production staff or has a turnover of less than $£ 2$ million)

- produce specialist or artisan products under their own company brand

- are of a size where local or regional supply is the best option for sustainability of the business

This description meant that by this time the scheme would be aimed at micro and small businesses rather than SMEs as referred to in the earlier communications.

International Journal of Management and Applied Research, 2014, Vol. 1, No. 1 


\section{Public and private food safety regulatory agencies}

All food businesses are subject to some form of public or statutory regulation and many of the food manufacturers and processors who supply retail establishments are also subject to food industry safety and quality compliance standards and policies demanded by the customers that buy their products.

The roles played by the various public regulatory and private or industry bodies that enforce or regulate public and private standards are similar. The primary objective of both being to protect consumers and in the case of private retailers to protect themselves in the event of a criminal or civil prosecution by being able to demonstrate that they, and their suppliers, have shown 'due diligence' in the sourcing of food supplies and the management of food safety (Mensah and Julien, 2011).

Therefore the standards provide a form of industry self regulation that generally exceed legal requirements to assist retailers in their fulfilment of legal obligations and protection of consumers as well as those of the food industry (Manning and Baines, 2004; Yapp and Fairman, 2005; Hutter and Amodu, 2008). Some standards - for example the sustainable sourcing of fish and seafood (Seafish Authority, 2011) - include quality, environmental and ethical issues.

Many of the Food Industry standards are internationally as well as nationally recognised and designed to meet best practice requirements. The British Retail Consortium (BRC)'s Global Food Standard is one of the most prominent. In this research we pay particular attention to the BRC because, apart from being a widely recognised standard, it was instrumental in SALSA's origins, it is a stakeholder and gives SALSA its continuous support.

BRC was developed in 1998 following the concerns of British retailers about the variations characterizing the different requirements and approaches to third party auditing with the intention becoming a recognised as a common minimum standard for food safety (Mensah and Julien 2011).

The main stakeholders of the BRC are their membership. It is administered and maintained by BRC Trading, a separate company from the Trade association, and handle all commercial aspects of the BRC (BRC Trading, 2013).

According to McDonald (2011), the BRC standard or certification scheme is accredited against ISO/IEC Guide 65:1996 (EN 45011:1998) and it is one of the internationally schemes recognised by the Global Food Safety Initiative (GFSI) as a benchmarked scheme for the evaluation of food businesses.

The GFSI is a business-driven initiative for the continuous improvement of food safety management systems to ensure confidence in the delivery of safe food to consumers 
worldwide (GFSI, 2014a). GFSI provides a platform for collaboration between some of the world's leading food safety experts from retailer, manufacturer, and food service providers associated with the food supply chain, international organizations, academia and government (GFSI, 2014b).

The evaluation and auditing of companies and their certification is not performed directly by BRC but carried out independently by Certification Bodies (CBs) who are accredited to the UK Accreditation Service (UKAS). UK Accreditation Service (UKAS) together with the BRC and its stakeholders regularly review the Standard, it protocol and the competence of the evaluators.

The key reason that the BRC Global Food Standard was developed was to reduce duplication of auditing by customers and their representatives (BRC 2012). Despite this other standards have been developed and include the International Food Standard (IFS), the Dutch Hazard analysis and Critical Control Point (HACCP), the Safety Quality Food (SQF) 2000 Level 2, and the ISO22000:2005 which is complemented with the PAS 220 Prerequisite Programmes (PRPs) on food safety for food manufacturing to form the Food Safety System Certification (FSSC) 22000 (Mensah and Julien 2011).

In spite of these developments a number of the major retailers continue to operate their own private food safety and quality standards. They do not accept or recognise other standards as being fully adequate in meeting the standards they require. For example Marks and Spencer, who have been operating and setting their own standards since 1949, claim that their own standards are the highest in the world, exceeding other industry hygiene standards and food safety requirements whether they are public regulations or other private food industry standards (Marks and Spencer, 2011).

\section{Background and History}

The idea of producing the scheme germinated and developed in the British Retail Corporation from the recognition by a number of food industry professionals for the need for a scheme or standard for smaller businesses (Swoffer, 2007). The factors that motivated them varied but the common purpose was to provide the UK food industry with an appropriate food safety certification scheme for small and local producers that is reliable, affordable and effective (SALSA, 2007).

An insight into the thinking and reasons for introducing the scheme and how the concept was developed were given in two proposal documents distributed in 2005 to stakeholders, potential stakeholders and other interested parties who contributed to its formation (K. Swoffer 2014 pers. com., $29^{\text {th }}$ May).

The first document circulated on the $17^{\text {th }}$ of June 2005 gives a concise but comprehensive overview and lists of the need for the scheme, a proposal for consideration by the 


\section{Safe and Local Supplier Approval - A case study of the third party supplier approval}

scheme for micro and small food businesses

interested parties, potential benefits and tasks that need to be addressed in order to achieve it aims and objectives.

The second document circulated on the $9^{\text {th }}$ of August 2005, drafted on behalf of the three original stakeholders; The British Hospitality Association, the British Retail Consortium and the Food and Drink Federation gives an insight into the early development and reasons for the need for the scheme, proposed criteria and objectives.

Both documents describe the proliferation of technical standards at the time and the requirements demanded by them as being disproportionate in terms of the number of them and in requirements to the needs of SMEs. It described the technical standards of the time as being 'pushed down' the supply chain to the point where the requirements became disproportionate to the needs of the SMEs and many customers.

The rhetoric in the second document changes, presumably as a result of discussions with the various interested parties and describes the above situation as a 'cascade' of technical standards. It is compared to the situation in the 1990s where major retailers all imposed their own technical standards and carried out their own evaluations leading to what is described as 'auditing overkill'. The second document describes the economic effect on SMEs by suggesting that not only are the current technical standards 'disproportionate' to SMEs they also led to increased costs caused by multiple evaluations and extreme difficulty in maintaining detailed knowledge of ever demanding legislation that was undergoing frequent change. Note: The latter is probably a reference to the then forthcoming introduction of HACCP in January 2006 (EU 852 2004).

Each document has a list of proposals and is essentially the same with two important exceptions.

1. The first document proposed the scheme would be recognized outside the UK as providing commercial confidence to overseas customers. This no longer appears in the Proposal section in the second document and SALSA have subsequently emphasized that the scheme is strictly for the UK only (SALSA, 2013). However the international proposal remained in the list of potential benefits suggesting that recognition outside the UK could provide commercial confidence in the businesses that were approved by SALSA.

2. The other change is that scheme should become self funding offering reasonable fees in a defined period of time with the securing of the necessary funds being listed as the first task to be tackled. 


\section{Previous Research}

Some limited research has been carried out by or on behalf of SALSA. This includes research by the London Metropolitan University in 2010 and McDonald in 2011. The study is not peer reviewed or published in any journals and is confined to describing the SALSA standard's requirements by each section and a basic analysis of the non conformities found during audits carried out between the $1^{\text {st }}$ of February 2007 and the $31^{\text {st }}$ of December 2008. It includes comments and opinions on the scheme made by an unspecified number of SALSA accredited mentors who gave their opinions on the principle difficulties faced by the food suppliers they had mentored or audited. The research findings had a useful practical application for the management of SALSA by identifying a number of recommendations for technical improvement to the standard and scheme. For example helping members to understand and implement the risk based HACCP system and how to establish the shelf life of products.

In 2011, McDonald compared the food safety standards including SALSA, SOFHT, EFSIS and STS Public Sector; McDonald concluded that these food safety schemes were all designed as being suitable for small businesses. However, McDonald (2011) highlighted that SALSA is not accredited. In a similar fashion, research carried out by Greenstreet Berman (2013) compared and evaluated a wide selection of Third Party auditing organizations and various Food Assurance Schemes. As a result SALSA was among the schemes that the researchers recommended should be recognised by the FSA. The intention or objective being that recognized Third Party Assurance Schemes can reduce, but not replace, the burden of inspection and enforcement role of national and local authorities.

The requirements for recognition, known as Earned Recognition, was to evaluate whether the Third Part Assurance Schemes (TPAS) are within the risk based inspection programmes of the local and national government agencies and, at a minimum, assure them that they conform with relevant food safety and hygiene law. The criteria used were based on and referenced to the applicable and current UK and European law and on the following constructs:

- Transparency;

- Consistency (across assessments) in requirements and decision making;

- Proportionate in what they require (risk based);

- Accountable - allowing firms to appeal decisions and hold the approval body "to account";

- Sustainable - by being self funding;

- Independent; and

- Demonstrably meet high standards of governance.

Further recognition of SALSA, is that STS - a major certification body which provides UK-wide supplier certification of food safety for food businesses - have combined with SALSA to produce revised versions of the SALSA standards for micro and small food businesses that want to work with public sector. This recognition implies that SALSA is 
now accepted by STS's large public sector clients, including the National Health Services (NHS) throughout the UK as well as local authorities (SALSA, 2013).

\section{SALSA and BRC}

Although BRC is a supporter and stakeholder of SALSA and a source of much of the inspiration in its creation and development they differ in many respects.

Economically, as a not for profit rather than a commercial organisation, SALSA is able to offer a less expensive service that is within the reach of micro and small businesses. Operating costs are contained and controlled by its structure with SALSA operating directly through their own Mentors and Auditors rather than through licensed Certification Bodies or other intermediaries. This also enables SALSA to have more direct control over auditing standards, pricing of audits and mentoring or consulting fees.

The main difference is that SALSA is not UKAS accredited. This is a significant difference in that under ISO 17021 UKAS accredited certification bodies are not allowed to offer any type of consultancy or anything that could be deemed as consultancy, guidance or any specific training to any organisation it intends to audit. This may be viewed with suspicion by some organisations (McGiso, 2013) as it could be inferred that there could be collusion between the SALSA mentors or consultants, auditors and the businesses but the same could be said of any other body which performs audits and is paid to do so by the business being audited.

Their policy of staying outside the rules of UKAS - ISO 17201 allows SALSA a more flexible and supportive approach by allowing mentoring services to be a part of its third party auditing procedure (SALSA). For the suppliers this avoids some duplication of effort, continuity of requirements and potentially savings in time and cost by dealing with one organisation rather than two, i.e. a consulting organization and an auditing body. SALSA does differentiate between consulting and auditing in that a SALSA mentor or consultant is ineligible to audit a supplier that they have previously supplied consulting services to.

This difference also permits and requires, unlike UKAS registered organizations, SALSA auditors, as part of the audit process, to make recommendations and draw up a mutually agreed list of actions against non conformances found during an audit. UKAS registered organisations give a list of non conformances but are not allowed to give advice on the corrective actions that are to be taken against any non conformances raised during an audit.

Therefore the SALSA scheme potentially benefits the businesses by enabling them to carry out corrective actions in house without having to seek further outside guidance or advice thereby potentially avoiding another audit with the additional costs of doing so.

This does not mean that a supplier cannot 'fail' an audit. If there are serious or major shortcomings are found during the audit or in the opinion of the auditor that a significant 
amount of work over a prolonged period of time to achieve conformance is required the auditor can either recommend that the business is re-audited in the future and/or by agreement with the supplier turn the audit visit into a mentoring visit. This latter situation means that the supplier immediately gains more information and guidance on how to achieve approval and has not completely 'lost' their audit fee (SALSA, 2011).

\section{Methods}

A qualitative case study methodology was used (Yin 2003) using a sample of individuals with experience and knowledge of SALSA. This was supported by a review of the extant literature, empirical evidence and data provided by SALSA both from the case interviews and documents provided to the researchers via personal communications from the interviewees.

A review of the extant literature was conducted on the origins and development of SALSA, research, issues faced by small and developing businesses and how SALSA addresses them. The founders or originators of SALSA supplied, in the form of personal communications, and copies of documents including notes of meetings and exchanges of e mail messages from the start up period and early stages of the development.

With the exception of a face to face interview with the Technical Manager of a supermarket group that utilizes both SALSA and BRC as approval standards for its suppliers all interviews were recorded.

In order to obtain data from different perspectives the case interviews consisted of the interviews with the current Director of SALSA and the former Technical Director of BRC who were the main principals involved in the founding and development of SALSA, a food safety professional working with the FSA, the owner of a small food supplier and approved SALSA member, and the technical representative from a retail company that utilize both SALSA and BRC as approval standards.

Semi structured questions were used in all cases with aim of eliciting their personal viewpoints with the question format being varied according to the context of their relationship with SALSA.

\section{Results - Case Interviews}

1. Interviews with the leaders of SALSA (pseudonyms Respondent 01 CG and Respondent $02 \mathrm{KS}$ ) with the aim to gain an insight into motivations for the development of SALSA, and how they foresaw its future.

The idea or recognition for the need for a standard that was more suitable for small businesses than anything else that existed at the time originated at the BRC as a result of an enquiry by Asda in 2004. Respondent 02 as the Technical Director of the BRC was approached by an ASDA executive to enquire if BRC had any plans to introduce a 'Mini 


\section{Safe and Local Supplier Approval - A case study of the third party supplier approval}

scheme for micro and small food businesses

BRC'. The Asda executive was finding that the smaller businesses had problems with getting to grips with its requirements which were either the same or similar as the BRC standard. This was causing a problem in that although approx $95 \%$ of their supplies were coming from large suppliers a Asda technical personnel were spending up to 3 days per week, dealing with technical issues in the vetting and approval of small suppliers. This was considered to be disproportionate resulting in approximately $60 \%$ of Asda's technical staff's time being spent on $5 \%$ of the business.

BRC's initial response was negative but Asda persisted with the enquiry and eventually Respondent 02 approached the two directors he was responsible to.

The Standards Director who worked for BRC Trading (the commercial arm of BRC) and the BRC Director of Food Policy. The former had no interest in the idea as he considered 'there was no money in it'. On the other hand the Policy Director was very interested because in his view British retailers were being accused of not being innovative enough and he gave KS the go ahead for its development and support.

In 2004 a meeting of possible stakeholders and other parties who might be interested was initiated by KS to outline the proposal for a standard or scheme for micro and small businesses. These included retailers, DEFRA, the FSA, the NHS, small business forums, business links, people with interests in small business including people from the Food and Drink Federation (FDF), the National Farmers Union (NFU) and the British Hospitality Association (BHA). Following a second meeting with the same parties in 2005 general agreement was reached that there was a need to fill the gap between what was described by $\mathrm{CG}$ as large and nothing.

This was the trigger for Respondent 01 and Respondent 02 to set about working together to develop something that they thought would be appropriate for the industry. Respondent 01 worked on the project under the auspices of the IFST and K S under the auspices of the BRC. All parties met together again in 2006 and worked on pushing the project forward and came up with the name SALSA - Safe and Local Supplier Approval. A partnership agreement was put together between the 4 owning partners- the BRC, the NFU, the FDF and the BHA. A contract was issued to the IFST to develop and run the Scheme and that's when it fell to Respondent 01 to actually set that up and run it SALSA as Director and launch the scheme in 2007.

Respondent 01 and Respondent 02 were asked how they considered SALSA differed from BRC and other standards.

Respondent 01 suggested that there are two ways of looking at it. Whether it was the same thing or is it something that is designed to be different. He pointed to two key differences. Firstly that it is not international and secondly, and more importantly in its structure which he claims provides a more supportive style unlike the more traditional style of auditing that only identified non conformances. SALSA auditing involves helping and advising throughout the audit. He considered this approach as being vital to 


\section{Safe and Local Supplier Approval - A case study of the third party supplier approval}

scheme for micro and small food businesses

making the scheme work because without this approach he felt the scheme would not work.

Respondent 02 pointed out other differences. He considered it being similar to BRC in that it is open to everyone whereas the customer or retailer owned private standards are not available to anyone else. Furthermore SALSA has a broader governance and stakeholder input from a wide range of expertise from across the food industry. $\mathrm{He}$ inferred that the input into most customer standards was limited to their In House resources while SALSA is developed on the lines of consensus while still maintaining an independence of decision making. In his view some customer or private standards are overzealous and the requirements are not hazard or risk based. For example he claimed that one major retailer demanded that all suppliers, regardless of the level of risk, have a metal detector. He considered this to be disproportionate as purchasing one when not justified by the associated risk could cost a small business its entire profit for a year. Respondent 02 also claimed that SALSA is more transparent with audit results being freely available to anyone who wants to see the companies that have gained certification and those who are working towards it.

Respondent 01 and Respondent 02 were asked about SALSA's future. Respondent's 01 view on the future of SALSA is that it will have to grow, adapt and to get to grips with the modern day food safety challenges and changes to meet the needs of legality and safety auditing certification. They have a number of high level priorities which they review on an annual basis. In his view one of their original objectives has been achieved in that that SALSA has become 'the scheme of choice' for micro and small food businesses.

The scheme will continue to be developed to meet with industry best practice. For example taking into account the findings of the Elliot Review (2014) on food security and its potential impact on areas like traceability and authenticity of food. The ultimate aim is to ensure that members continue to get support and advice at all levels from basic upwards in response to their needs.

They also have boundaries for the scheme based in its core objectives. It will not, for example, stray into other areas like ethical trading or environmental matters. Respondent 01 emphasised again that the scheme is strictly confined to the UK and would not be going global like BRC. This does not mean that SALSA will not cooperate with others who might want to set up a similar scheme in their own countries. In essence they want to stay relevant to the needs of the sector.

Respondent 02 has a similar vision for SALSA. In his experience schemes like this take time to fully develop and gain acceptance. For BRC it took 2 or 3 years. In his view SALSA has passed that stage and it needs to grow. He was more enthusiastic than CG about expanding overseas for example, for UK companies that have sites overseas. However this could upset the current financial model that is built on local auditors and

International Journal of Management and Applied Research, 2014, Vol. 1, No. 1 
local mentors who are not paid travel expenses but he did not consider this as a reason why it cannot be done.

KS would also love to see SALSA offering a series of services for small businesses. For example discounts on insurances, pest control, protective clothing services and products for small businesses. The subsidized training they are currently providing could be widened to include e-learning and management training for supervisors. He proposed there is potential for what he described as 'the club' to be enlarged by offering a broader range of services that would help businesses keep their costs down.

2. One interview with a FSA representative (Respondent 03) was directed on how SALSA was viewed by the FSA and its potential role in aiding regulatory enforcement. Respondent 03 is aware of the existence of SALSA since it was launched and the broad principles of how it works but no experience of any direct involvement. Respondent 01 was asked whether she agreed with the view expressed in FSA research (Greenstreet and Berman 2013) that SALSA could be used to enhance the enforcement role played by EHOs and other enforcement officers known as Earned Recognition. She confirmed that it is something that the FSA is looking at but considers it to be important that the right checks and balances are built in to ensure that the assurance from the industry scheme meet the needs of the regulators.

Respondent 03 did not have any views on the differences between the auditing approach of BRC and SALSA but recognised SALSA as having a supportive approach in the same way that EHOs are required to. It has been also suggested that it could be good if schemes like SALSA could share their reports with the EHOs but this could brings up questions of confidentiality.

3. Interview with a representative (Respondent 04) of Boothson SALSA who at that time were buying from 30 to 35 SALSA approved suppliers. The respondent considered it to be a fair scheme for raising standards of food safety in that it is:

- Not for profit

- Helps compliance

- Due diligence

- Encourages continuous improvement.

- Gives good guidance at no additional cost.

Out of these points he viewed continuous improvement to be the most important part of following the SALSA scheme. He considered that most suppliers /food businesses and retailers use standard certification as a 'get of jail free card' rather than a positive means of improving and maintaining high standards of food safety and quality. Particularly when retailer 'own label' products are involved and the retailer's liability is increased.

Booths policy is to encourage business in the North West and help family businesses (Booths being a family business themselves). Their longer term aims are focussed on improvement, providing added value and they consider they have a joint destiny with 
their suppliers and customers. Booths directly help their suppliers by delivering free mentoring for their suppliers or potential suppliers and help with development problems. They recognise the value of SALSA but also recommend that some suppliers get BRC certification where appropriate. This is not just dependent on size in terms of employee numbers and turnover but includes production volume, square footage, number and complexity of products. At the time of interview they had 30 -35 SALSA approved suppliers.

In general Respondent 04 felt that that many suppliers are saddled with overloaded, more costly and more complicated system than they need. Apart from higher cost this can potentially make their system unmanageable with an unnecessary number of checks and excessive documentation.

4. Interview with small food business owner (Respondent 05) focused on their experience of implementing the SALSA standard and the ways it had affected their business and its development. Background of the case: started business in January 2010, started supplying ready meals to Booths in February 2010, gained first SALSA Approval in July 2011.

The business is an Approved Premises (EC 253 2004) and produces 'own brand' ready meals for the Booths supermarket chain in northern England. Respondent 05 accredited SALSA for much of their success and regards the most valuable contribution that SALSA made for his business is giving them a practical framework for the implementation of good food safety standards alongside quality as well as meeting legal requirements. Previously the respondent had worked as a chef in restaurants where, at that time, there was a lack of knowledge, support or a framework like SALSA to follow. Respondent 05 claimed that as a consequence food hygiene standards were not given the priority they should be. Respondent's experience was that SALSA was also very useful in helping to achieve legal requirements and he found that Environmental Health Officers and other governmental bodies felt 'more comfortable' knowing that his business was working with SALSA. In answer to whether this business would consider progressing to BRC Respondent 05 did not consider it necessary at this time. Respondent felt that SALSA is fine for their current needs as a standalone accreditation but decision to move to BRC would depend on the growth of the business and future demands of customers.

\section{Discussion}

Its steady growth has enabled SALSA to emerge as the largest food safety approval scheme of its kind in the U.K. It has enabled an increased number of micro and small businesses to demonstrate that they can produce safe food and thereby gain access to market opportunities they did not have before.

Although SALSA originated with BRC it has developed into more than a standard for policing food safety in the food manufacturing industry. It offers a direct supportive role through its mentoring, training and web based services but more crucially as part of its different approach to auditing. 
Hutter and Amodu (2008) proposed that better regulation calls for less inspection and more advice. Historically SMEs have relied on state regulatory systems for education and advice and have less contact with non state sources than larger businesses. They might not be members of trade associations or consultancies which provide training on food hygiene and food safety matters. Much of SALSA'a success can be attributed to recognising and fulfilling this need.

The SALSA approach with its mixture of support and policing also fits with the principles of current legal requirements that are based on the self regulation approach required by risk based systems rather than the prescriptive 'Command and Control' approach that was the basis of enforcement prior to the introduction of the 1995 (Food Safety (General Food Hygiene) Regulations and Food Safety (Temperature Control Regulations) and in 2006 the requirement for food businesses to have a HACCP based food safety management system (EU Regulation 852 /2004).

This approach to regulation has been described as 'enforced self regulation' and is a mix of state and business regulatory efforts. The government lays down broad standards which companies must then satisfy. Businesses are expected to develop risk management systems and rules to secure, monitor and review compliance. Where this is not being achieved, companies are expected to have procedures in place to deal with noncompliance (Hutter and Amodou 2008; Yapp and Fairman 2005). This gives the business the opportunity and flexibility of designing a food management system that is suitable and fits the needs of its business while meeting legal and best practice requirements that are the basis of current law (EC 852 / 2004), including those of HACCP.

The requirements of the law like those of the SALSA approach are not rigidly prescriptive. It remains the responsibility of the business to carry out its own risk assessments and hazard analysis to determine how and where controls are to be implemented. For example the SALSA Standard requires that all personnel shall be adequately supervised throughout the working period but the SALSA guidance states that this is 'as required' by the work activity and activities crucial to the safety of the product being made (SALSA, 2012). This is a risk based approach rather than a prescriptive one.

It is very probable that the success in establishing SALSA would not have been achieved without a high degree of cooperation and between various public and private organizations and the businesses themselves. This ability to work together towards a common goal is not always present in the food industry and its importance has been emphasized in some previous research. For example Yapp and Fairman (2004) examining barriers to food safety found that $83 \%$ of SMES demonstrated an active lack of trust in both the governmental Environmental Health Professionals and in both prescriptive and self-regulatory elements of legislative requirements. Motarjemi and Mortimore (2005) propose that ensuring food safety can only be successful if there is a true cooperation between the different sectors involved including governments, industry and consumers. 
Panisello and Quantick (2001) propose that HACCP implementation will be impeded unless there is a mutual understanding and agreement between the food industry and the enforcement authorities. Tompkin (2001) suggests that government and industry share a common goal, to ensure the safety of food and suggests that in order to do so each must fulfil separate but complementary roles. Wright et al. (2006) also confirms the advantages of working in partnership, rather than separately, with the food industry in that it has the potential to achieve a variety of aims that include, resolving industry specific issues, supporting or advancing industry, improving compliance or enforcement, developing codes of practice, regulations and standards, or addressing specific problems in society through awareness raising or education.

\section{Conclusion}

The current structure and processes of SALSA with its stakeholders taken from key players in the food, retailing and scientific communities represents an effective model of cooperation and support which might usefully be applied to other third-party auditing standards particularly in the case of risk-based management systems requiring specific rather than general guidance on risk and hazards.

\section{References}

1. BRC Global Standards (2011), Global Food Standards, available at: www.brcglobalstandards.com (Accessed on $25^{\text {th }}$ July 2011)

2. BRC Trading (2013), BRC Trading Ltd, available at: http://www.brc.org.uk/brc_directors.asp (Accessed on 14th December 2013)

3. Elliot, C. (2014), Elliot Review into the Integrity and Assurance of Food Safe of Food Supply Networks - Final Report. London: HM Government.

4. Fielding, L.; Ellis L.; Clayton D. and Peters, A. (2011), “An evaluation of process specific information resources, aimed at hazard analysis, in Small and Medium Enterprises in food manufacturing", Food Control, Vol. 22, No. 8, pp. 1171-1177. https://doi.org/10.1016/j.foodcont.2011.01.011

5. Global Food Safety Initiative (GFSI) (2014a), Global Food Safety InitiativeRecognised Schemes, available at: http://www.mygfsi.com/about-gfsi/gfsirecognised-schemes.html (Accessed on 17th June 2014).

6. Global Food Safety Initiative (GFSI) (2014b), GFSI Global Markets Capacity Building Programme Protocol, available at: http://www.mygfsi.com/gfsifiles/GFSI_Global_Markets_Protocol.pdf (Accessed on 10th August 2014). 
Safe and Local Supplier Approval - A case study of the third party supplier approval scheme for micro and small food businesses

7. Greenstreet Berman Ltd (2013), Assessment and comparison of third party assurance schemes in the food sector: Towards a common framework, London: Greenstreet Berman Ltd.

8. Grimes, C. (2011), Small Business Schemes, available at: http://www.ifst.org/sites/default/files/chrisgrimessmallbusinessschemessalsaprese ntation.ppt. (Accessed on 10th September 2014).

9. Hutter, B.M. and Amodu, T. (2008), Risk Regulation and Compliance: Food Safety in the UK, London: London School of Economics and Political Science.

10. Institute of Food Science and Technology (IFST) (2013), Institute of Food Science and Technology, available at: http://www.ifst.org/ (Accessed on $29^{\text {th }}$ October 2013).

11. London Metropolitan University (2010), A critical review of the SALSA Scheme and its benefit to small businesses, available at: http://www.salsafood.co.uk/downloads/SALSA\%20Research\%20Final\%20Copy. pdf (Accessed on $30^{\text {th }}$ July 2014).

12. Marks and Spencer (2011), Food manufacturing: our food policy, available at: www.marksandspencer.com/Food manufacturing-Our-Food-Policies (Accessed on $30^{\text {th }}$ November 2011).

13. McDonald, J. (2011), Food Safety scheme comparison document, available at: http://www.salsafood.co.uk/downloads/Food\%20Safety\%20Scheme\%20comparis on\%20table\%20final\%2014\%202\%2011\%20FINAL.pdf. (Accessed on 12 August 2014).

14. McGiso (2013), United Kingdom Accreditation Service (UKAS), available at: http://www.mcgiso.com/index.php/ukas-information (Accessed on 4th November 2013).

15. Mensah, L.D, and Julien, D. (2011), "Implementation of food safety management systems in the UK", Food Control, Vol. 22, No. 8, pp.1216-1225. https://doi.org/10.1016/j.foodcont.2011.01.021

16. Motajemi ,Y and Mortimore,S (2005), "Industry's need and expectations to meet food safety, $5^{\text {th }}$ International Meeting: Noordwijk food safety and HACCP Forum 9-10 December 2002", Food Control, Vol. 16, No. 6, pp 523-529. https://doi.org/10.1016/j.foodcont.2004.10.014

17. Panisello,P. and Quantick,P. (2001), "Technical Barriers to hazard analysis critical control point (HACCP)", Food Control, Vol. 12, No. 3, pp.165-173. https://doi.org/10.1016/S0956-7135(00)00035-9 
18. Psomas, E.L.; Fotopoulos, C.V. and Kafetzopoulos (2010), "Critical Factors for effective implementation of ISO 9001 in SME service companies", Managing Service Quality, Vol. 20 No. 5, pp.440-457. https://doi.org/10.1108/09604521011073731

19. SALSA (2007), Opportunities for SMEs, available at: http://www.sustainweb.org/pdf2/gft_Simon_Doff.ppt (Accessed on 14 ${ }^{\text {th }}$ September 2014).

20. SALSA (2011), Frequently Asked SALSA Questions, available at: http://www.salsafood.co.uk/tiny_mce/plugins/filemanager/files/SALSA_FAQ.pdf (Accessed on $14^{\text {th }}$ August 2014).

21. SALSA (2012), Audit Standard, available at: http://www.salsafood.co.uk/tiny mce/plugins/filemanager/files/SALSA Audit St andard_Issue 3_2012_Rev_1.pdf (Accessed on 14 ${ }^{\text {th }}$ August 2014).

22. SALSA (2013), SALSA acceptance widens to the public sector, available at: http://www.salsafood.co.uk/newsDetail.php? $\mathrm{n}=230$ (Accessed on $14^{\text {th }}$ August 2014).

23. SALSA (2014a), About SALSA, available at: http://www.salsafood.co.uk/about.php?p=1 (Accessed on 14 ${ }^{\text {th }}$ August 2014).

24. SALSA (2014b), Supplier Benefits, available at: http://www.salsafood.co.uk/suppliers.php? $\mathrm{p}=2$ (Accessed on $14^{\text {th }}$ August 2014).

25. Seafish Authority (2011), The authority on seafood, available at: www.seafish.org (Accessed on $1^{\text {st }}$ December 2011).

26. Swoffer, K. (2007), Source Locally and Sell Nationally, available at: http://www.fdin.org.uk/output/SLSN_2007/Salsa\%20Scheme\%20\%20Background,\%20Benefits\%20\&\%20How\%20It\%20Works.pps (Accessed on $1^{\text {st }}$ August 2014).

27. Taylor, E. (2001), "HACCP in small companies: benefit or burden?", Food Control, Vol. 12, No. 4, pp. 217 -222. https://doi.org/10.1016/S09567135(00)00043-8

28. Taylor, E and Kane, K, (2005), "Reducing the burden of HACCP on SMEs", Food Control, Vol. 16, No. 10, pp. 833-839.

https://doi.org/10.1016/j.foodcont.2004.06.025 
29. The European Commission (2005), The New SME Definition, available at: http://ec.europa.eu/enterprise/policies/sme/files/sme definition/sme user guide e $\underline{\text { n.pdf }}$ (Accessed on 23rd December 2013)

30. Tompkin, R. (2001), "Interactions between government and industry food safety activities", Food Control, Vol. 12, No. 4, pp. 203-207.

https://doi.org/10.1016/S0956-7135(00)00038-4

31. Yapp, C. and Fairman, R. (2004), The Evaluation of Effective Enforcement Approaches for Food Safety in SMEs, London: Kings College London.

32. Yapp, C. and Fairman R. (2005), "Assessing compliance with food safety legislation in small businesses", British Food Journal, Vol. 107, No. 3, pp. 150 161. https://doi.org/10.1108/00070700510586470

33. Yapp, C. and Fairman R. (2006), "Factors affecting food safety compliance within small and medium-sized enterprises: implications for regulatory and enforcement strategies", Food Control, Vol. 17, No. 1, pp $42-51$. https://doi.org/10.1016/j.foodcont.2004.08.007

34. Yin, R.K. (2003), Case Study Research: Design and Methods, California: Sage Publications Inc. 